Article

\title{
Optical, Electrical, and Surface Properties of Cu/Plasma Polymer Fluorocarbon Nanocomposite Thin Film Fabricated Using Metal/Polymer Composite Target
}

\author{
Sung Hyun Kim, Mac Kim, Jae Seong Park and Sang-Jin Lee* \\ Chemical Materials Solutions Center, Korea Research Institute of Chemical Technology, Daejeon 34114, Korea; \\ wdy1332@krict.re.kr (S.H.K.); kimmac79@krict.re.kr (M.K.); jspark@krict.re.kr (J.S.P.) \\ * Correspondence: leesj@krict.re.kr; Tel.: +82-42-860-7902, Fax.: +82-42-860-7909
}

Received: 27 February 2019; Accepted: 26 March 2019; Published: 28 March 2019

check for updates

\begin{abstract}
We propose a new method of fabricating metal-polymer composite targets for sputtering, which makes it easier to control the composition and enables the homogeneous and reproducible fabrication of metal-polymer nanocomposites over large areas. Using $\mathrm{Cu}$ /polytetrafluoroethylene composite targets containing 20,50, and $80 \mathrm{wt} . \% \mathrm{Cu}, \mathrm{Cu} /$ plasma polymer fluorocarbon (PPFC) nanocomposite thin films were prepared by radio-frequency (RF) sputtering. Targets with $80 \mathrm{wt} . \%$ $\mathrm{Cu}$ were conductive; moreover, sputtering was possible not only with RF but also with mid-range frequency (MF) and direct current (DC) power sources. The nanocomposite thin film deposited by MF and DC power using an $80 \mathrm{wt} . \% \mathrm{Cu}$ target showed near-metallic characteristics, exhibited absorption peaks at 618 and $678 \mathrm{~nm}$, and had a surface resistance of $2 \times 10^{4}$ and $34.55 \Omega / \mathrm{sq}$, respectively. We also analyzed the structure and composition of the $\mathrm{Cu} / \mathrm{PPFC}$ nanocomposite films by X-ray diffraction and X-ray photoelectron spectroscopy. The described metal-polymer targets can advance the applications and commercialization of nanocomposite thin films.
\end{abstract}

Keywords: $\mathrm{Cu}$ /polytetrafluoroethylene composite target; plasma polymer fluorocarbon; nanocomposite thin film; sputtering power source; surface plasmon resonance

\section{Introduction}

Polymer-metal nanocomposites exhibit excellent optical [1-8], electrical [1,4], and mechanical properties $[9,10]$ and have been attracting much attention owing to their various characteristics such as surface hardness [6], bioactivity [11,12], perfect absorbance, [13-15], and sensing ability [16]. Polymers with good insulating properties are well suited as host materials for supporting a variety of metal clusters [5,17]. The excellent properties of polymer-metal nanocomposites depend on the size, quantity, and shape of various metal clusters contained in the polymer matrix; various studies elucidating these properties have been performed $[17,18]$, with reference to surface antimicrobials and abrasion-resistant coatings, and gas sensor films [19-22].

As a polymer matrix, polytetrafluoroethylene (PTFE), which is mechanically, thermally, and chemically stable, and has excellent insulation and optical properties, is widely used $[1,3,6,9,11,19,23]$. Studies using noble metals such as $\mathrm{Ag}[5,9,11,19,24-26], \mathrm{Au}[3,16,27]$, and $\mathrm{Cu}[12-14]$ have been carried out, but mostly, Ag and Au have been used. In addition to noble metals, nanocomposites using $\mathrm{SiO}_{2}$ [6], graphite [10], $\mathrm{ZnO}$ [19], Ti [28], $\mathrm{Fe}-\mathrm{Ni}-\mathrm{Co}$ [29], and $\mathrm{TiO}_{2}$ [30], with PTFE, have also been reported.

A nanocomposite can be fabricated by the physical vapor deposition (PVD) method, as PVD allows for control of the dopant, enables uniform coating, and minimizes the reaction with air. The co-sputtering method employing two sputtering cathodes $[3,6,9,10,12-14,19,28]$ is the 
most widely used method, and other methods involve the use of an evaporator $[9,25]$, sputter evaporator, ion beam co-sputtering [16], and pulsed laser deposition [24], to fabricate a polymer-metal nanocomposite. However, the use of two sputtering cathodes or a combination of two deposition methods to fabricate nanocomposites requires precise control for yield matching; moreover, it is difficult to ensure reproducibility of the experimental results owing to the complicated equipment configuration and difficulty in securing uniformity over a large area, which are stumbling blocks toward commercialization.

In a previous study, our group found that a plasma polymer fluorocarbon (PPFC) thin film prepared using a carbon nanotube (CNT)/PTFE composite sputtering target exhibited diverse physical properties depending on the content of the CNT. In addition, it has been reported that CNT, when added to a composite target, imparts conductivity; hence, sputtering is also possible using a mid-range frequency (MF) power source [31]. Taking our previous study forward, in this study, a Cu/PTFE composite target for sputtering was first introduced for fabricating a $\mathrm{Cu} / \mathrm{PPFC}$ nanocomposite thin film by uniformly dispersing $\mathrm{Cu}$ metal powder in PTFE powder and pressing at high temperature. Previously, the composite target was prepared by attaching half of the polymer target to half of the metal target, or attaching a metal foil or wire to the surface of the polymer target $[1,6]$. However, in those studies, it was challenging to deposit a nanocomposite thin film of uniform composition ratio over a large substrate area and prepare a reproducible target; therefore, practical composite targets have been difficult to achieve thus far. We fabricated noble polymer-metal composite targets with 20,50, and $80 \mathrm{wt} . \% \mathrm{Cu}$ in PTFE powder. Thus, the filling ratio of the metal nanoclusters in the nanocomposite thin film can be easily controlled, and the nanocomposite thin film can be prepared by long-duration sputtering with one target in the same manner as the conventional sputtering target, enabling excellent reproducibility. Finally, because of the controllability and simple equipment configuration, large-area sputtering is possible; hence, this method can be employed in a wide variety of polymer-metal nanocomposite technical and commercial applications.

In this study, we investigated the physical and chemical properties of the $\mathrm{Cu} / \mathrm{PPFC}$ nanocomposite thin films with various $\mathrm{Cu}$ contents, and analyzed how the properties of the films change with radio-frequency $(\mathrm{RF}), \mathrm{MF}$, and direct current (DC) power sources using the $\mathrm{Cu} / \mathrm{PTFE}$ (20:80, $\mathrm{w} / \mathrm{w})$ target.

\section{Materials and Methods}

\subsection{Preparation of $\mathrm{CU} / \mathrm{PTFE}$ Composite Sputtering Targets}

Cu powder (e-Cu25, Chang Sung) was mixed with PTFE powder (A7, DuPont) at weight ratios of 20:80, 50:50, and 80:20, respectively, following which composite sputtering $\mathrm{Cu} / \mathrm{PTFE}$ targets were prepared by a high-temperature compression molding method. Compression pressure was $200 \mathrm{kgf} / \mathrm{cm}^{2}$ and molding temperature was $370{ }^{\circ} \mathrm{C}$. A pure PTFE sputtering target devoid of any $\mathrm{Cu}$ powder was also prepared by the same method for reference. Disk-type $\mathrm{Cu} / \mathrm{PTFE}$ composite sputtering targets with a diameter of $10.16 \mathrm{~cm}$ and thickness of $0.64 \mathrm{~cm}$ were then fabricated by milling. For simplicity, the targets were labeled PTFE ( $\mathrm{Cu} 0), \mathrm{Cu} 20, \mathrm{Cu} 50$, and $\mathrm{Cu} 80$ according to the composition ratio. Figure 1a sequentially shows the fabrication of the $\mathrm{Cu} / \mathrm{PTFE}$ composite target. 
(a)

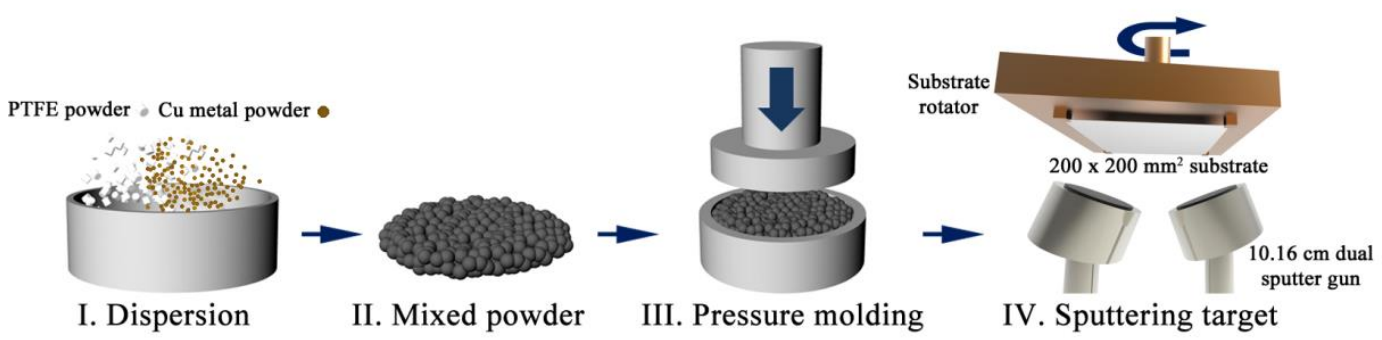

(b)
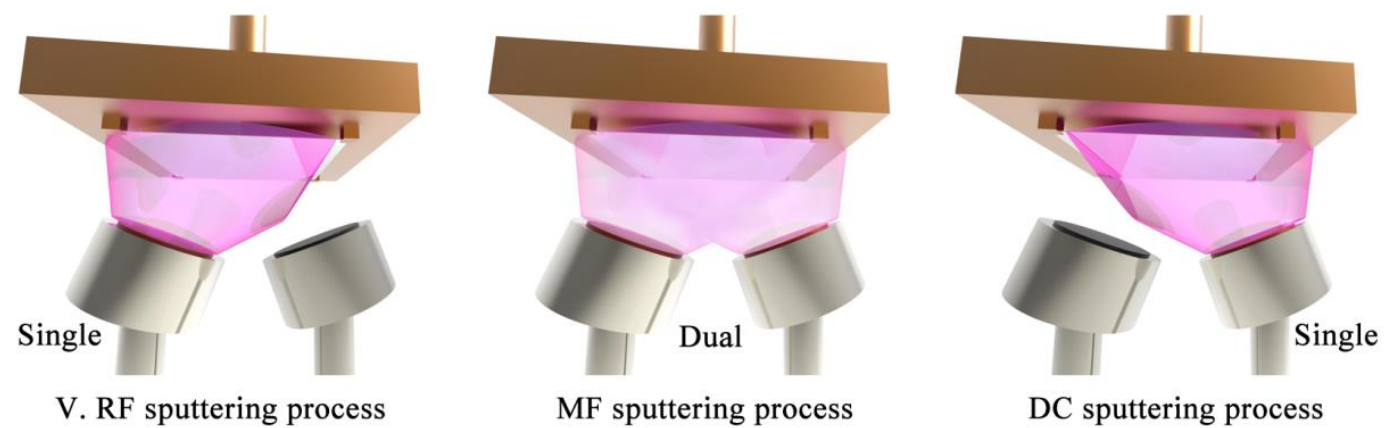

MF sputtering process

DC sputtering process

Figure 1. (a) Sequential diagram of the fabrication of $\mathrm{Cu} / \mathrm{PTFE}$ composite target. (b) Illustration of the sputtering process to deposit $\mathrm{Cu}$ /plasma polymer fluorocarbon (PPFC) nanocomposite thin films with radio frequency $(\mathrm{RF})$, mid-range frequency $(\mathrm{MF})$, and direct current $(\mathrm{DC})$ power sources.

\subsection{Fabrication of $\mathrm{Cu} / \mathrm{PPFC}$ Nanocomposite Thin Films}

The sputtering chamber was evacuated to a base pressure of $6.6 \times 10^{-3}$ Pa by a mechanical pump and a cryogenic pump. The partial pressure of Ar during the process was $0.93 \mathrm{~Pa}$. The $\mathrm{Cu} / \mathrm{PPFC}$ nanocomposite thin films were fabricated using RF (13.56 MHz), MF (40 kHz), and DC power with a sputtering power density of $1.23 \mathrm{~W} / \mathrm{cm}^{2}$. Dual magnetron cathodes were used for MF sputtering to improve sputtering efficiency. Target-to-substrate distance was fixed at $24 \mathrm{~cm}$. A schematic diagram of the sputtering process for each power source is shown in Figure 1b. We used a polyethylene terephthalate (PET, KIMOTO, Japan) film substrate of size $20 \times 20 \mathrm{~cm}^{2}$ and thickness $125 \mu \mathrm{m}$. In order to compare the physical properties of the thin films with different $\mathrm{Cu}$ composition ratios, pure PTFE, $\mathrm{Cu} 20, \mathrm{Cu} 50$, and $\mathrm{Cu} 80$ composite targets were sputtered with an RF power source to fabricate the thin films. Deposition rates for each composite target and sputtering power source were determined by using the Alpha step method (Dektak XT, Bruker, MA, USA). A thickness step is generated by covering a part of the sample for measurement. To investigate the physical properties of the $\mathrm{Cu} / \mathrm{PPFC}$ nanocomposite thin films according to power source, $100 \mathrm{~nm}$ thin films were fabricated by sputtering with $\mathrm{RF}, \mathrm{MF}$, and DC power sources using the $\mathrm{Cu} 80$ composite target. The fabricated thin films were named "target name + power source type" for clarity and conciseness. For example, a thin film made

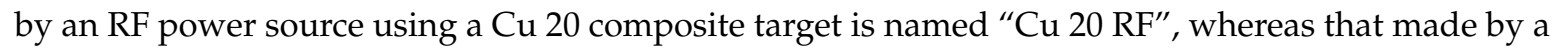
DC power source using a $\mathrm{Cu} 80$ composite target is named " $\mathrm{Cu} 80 \mathrm{DC}$ ".

\subsection{Characterization of $C$ U/PPFC Nanocomposite Thin Films}

The nanocomposite structure of $\mathrm{Cu} / \mathrm{PPFC}$ thin film was investigated by field-emission transmission electron microscopy (FE-TEM, Tecnai G2 F30 S-Twin, FEI Co., Hillsboro, OR, USA). Optical properties of the thin films were measured by UV-VIS spectroscopy (U-4100, Hitachi, Tokyo, Japan). Standard deviation of water contact angle, sheet resistance, optical transmittance, and $b^{*}$ (yellow index) were measured by five points at each sample. The measuring points were the center and four sides of the film. The surface energy of the nanocomposite thin film was measured using a contact angle analyzer (Phoenix 300 Touch, Surface Electro Optics, Suwon, Korea). The volume of water droplets was $2 \mu \mathrm{L}$, and the images were automatically analyzed by the system. Structural characteristics 
of the $\mathrm{Cu} / \mathrm{PPFC}$ nanocomposite thin films were analyzed by X-ray photoelectron spectroscopy (XPS, AXIS Nova, Kratos, Manchester, UK) and X-ray diffraction (XRD, SmartLab, Rigaku, Tokyo, Japan).

\section{Results}

The $\mathrm{Cu} 20$ and $\mathrm{Cu} 50$ composite targets showed no electrical conductivity, while the $\mathrm{Cu} 80$ targets showed a good sheet resistance of $2.1 \times 10^{-3} \Omega /$ sq. Therefore, first, the nanocomposite thin film was fabricated using an RF power source, and the change in the physical properties of the thin film according to the $\mathrm{Cu}$ composition in the composite target was investigated. Figure 2a shows a cross-sectional TEM image of the $\mathrm{Cu} 80 \mathrm{MF}$ thin film. The inserted element mapping image displays homogenous distribution of copper and fluorine atoms in the thin film. Cu metal nanoclusters were distributed in a spherical shape with a size of $10-20 \mathrm{~nm}$. Figure $2 \mathrm{~b}$ shows a lattice of nanocluster $\mathrm{Cu}$ in PPFC thin film matrix. The central $\mathrm{Cu}$ nanocluster domain, which is marked yellow, shows (111) plane orientation with a lattice distance of $0.208 \mathrm{~nm}$. In this TEM image, we confirmed that $\mathrm{Cu}$ nanoclusters were well formed as a crystalline phase in the plasma polymer fluorocarbon matrix.

(a)

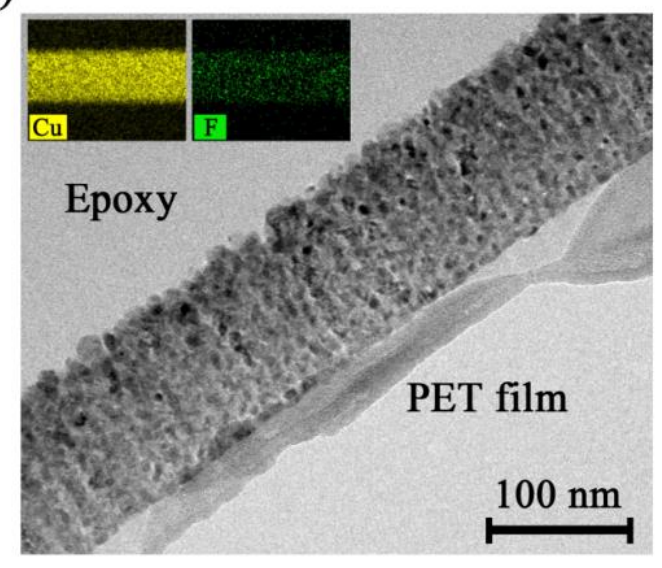

(b)

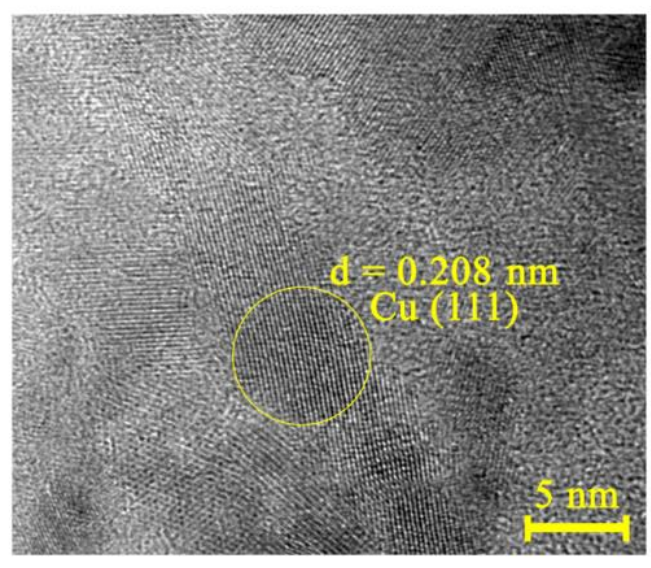

Figure 2. (a) Cross-sectional TEM image of the $\mathrm{Cu} 80 \mathrm{MF}$ thin film and element mapping images, (b) nanocluster $\mathrm{Cu}$ in PPFC thin film matrix.

Figure 3 shows the optical properties for a $100 \mathrm{~nm}$ thick $\mathrm{Cu} / \mathrm{PPFC}$ nanocomposite thin film. Figure 3a shows the optical transmittance graph of the $\mathrm{Cu} / \mathrm{PPFC}$ nanocomposite thin film deposited by RF sputtering. For comparison, the results for the thin films deposited using a pure PTFE target devoid of $\mathrm{Cu}$ are also shown. The optical properties of the $\mathrm{Cu} 20 \mathrm{RF}$ and $\mathrm{Cu} 50 \mathrm{RF}$ nanocomposite thin films were very similar to those of PTFE RF thin films. They exhibited a high transmittance of $90 \%$ or more in the visible light region and showed excellent transmission characteristics even in the infrared (IR) region. For the $\mathrm{Cu} 80 \mathrm{RF}$ thin film, visible light transmittance was drastically decreased, and the transmittance was about $70 \%$ at a wavelength of $500 \mathrm{~nm}$. As the $\mathrm{Cu}$ content increased, the characteristics of $\mathrm{Cu}$ in the nanocomposite thin film became more remarkable. Figure $3 \mathrm{~b}$ shows the optical transmittance characteristics of the nanocomposite thin films deposited by RF, MF, and DC sputtering with a $\mathrm{Cu} 80$ target, which has a low electrical resistance. The $\mathrm{Cu} 80 \mathrm{MF}$ thin film exhibited a transmittance of less than $20 \%$ in the visible light region, whereas the $\mathrm{Cu} 80 \mathrm{DC}$ thin film had a transmittance of less than $10 \%$, which was similar to that of the $\mathrm{Cu}$ thin film. Thus, the transmittance is high in the order of $\mathrm{Cu} 80 \mathrm{RF}>\mathrm{Cu} 80 \mathrm{MF}>\mathrm{Cu} 80 \mathrm{DC}$, confirming that the physical properties of the films differ depending on the power source even when a composite target of the same composition is used. Remarkably, the $\mathrm{Cu} 80 \mathrm{MF}$ nanocomposite thin film showed an electrical conductivity of $2 \times 10^{4} \Omega / \mathrm{sq}$, whereas the electrical resistance of the $\mathrm{Cu} 80 \mathrm{DC}$ thin film was as low as $34.55 \Omega / \mathrm{sq}$. Thus, the content and role of $\mathrm{Cu}$ in the nanocomposite thin films fabricated using the MF and DC power sources are greater than that in those obtained using RF. All other samples showed no electrical 
conductivity. Figure $3 \mathrm{c}$ plots the optical absorption of the $\mathrm{Cu} / \mathrm{PPFC}$ nanocomposite thin films as a function of the target composition and power source. The $\mathrm{Cu} 80 \mathrm{MF}$ nanocomposite thin film exhibited an absorption peak at $618 \mathrm{~nm}$, whereas that for the $\mathrm{Cu} 80 \mathrm{DC}$ thin film was at $678 \mathrm{~nm}$. This is attributed to the surface plasmon resonance phenomenon of the metal nanoclusters [1,2] and confirms that the $\mathrm{Cu}$ nanoclusters are well formed in the PPFC matrix. It is expected that the size of the agglomeration of $\mathrm{Cu}$ nanoclusters in $\mathrm{Cu} 80 \mathrm{DC}$ is larger than that in $\mathrm{Cu} 80 \mathrm{MF}$ because the peak position is red shifted. The large size of the $\mathrm{Cu}$ nanoclusters also affects the conductivity of the nanocomposite thin films. Figure $3 \mathrm{~d}$ compares the transmittance and color of each sample. The PTFE RF, Cu $20 \mathrm{RF}$, and $\mathrm{Cu} 50 \mathrm{RF}$ nanocomposite thin films are quite transparent and colorless. However, the $\mathrm{Cu} 80 \mathrm{RF}$ sample is slightly yellow, and the $\mathrm{Cu} 80 \mathrm{MF}$ and $\mathrm{Cu} 80 \mathrm{DC}$ samples are red in color and exhibit low transmittance.

(a)

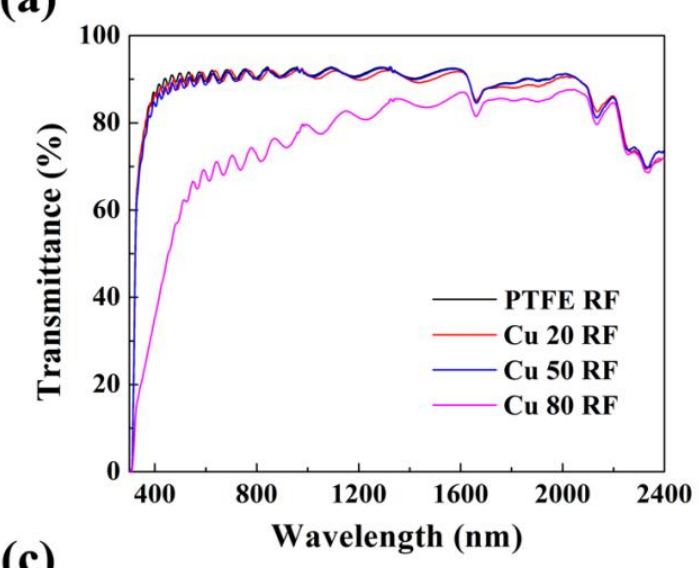

(c)

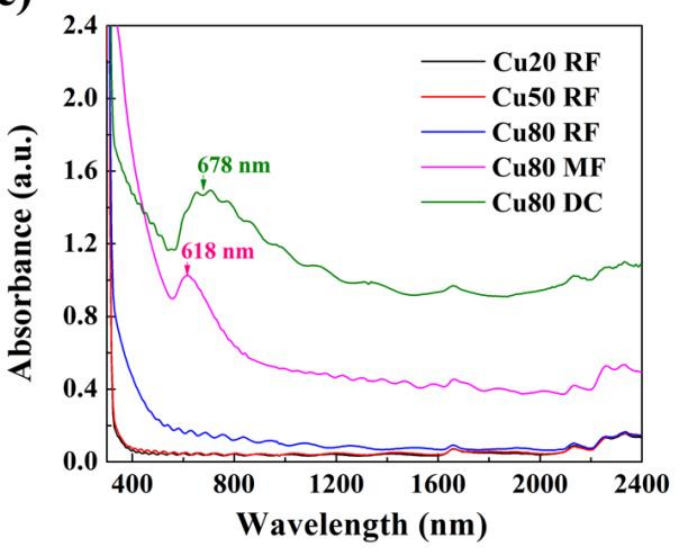

(b)

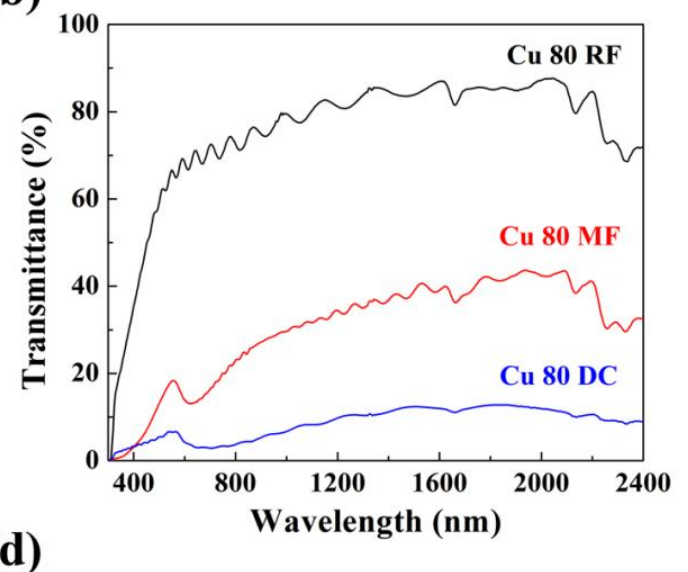

(d)

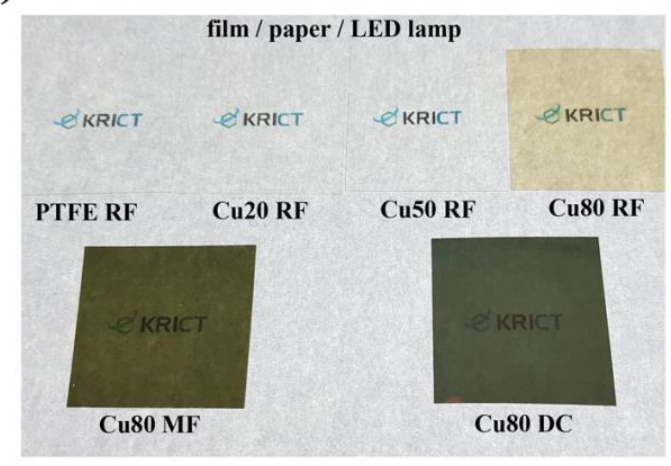

Figure 3. (a) Transmittance spectra in the wavelength range $300-2400 \mathrm{~nm}$ according to Cu content, (b) transmittance spectra according to power sources using the $\mathrm{Cu} 80$ target, (c) absorption spectra according to $\mathrm{Cu}$ content and power sources, and (d) photographs of the $\mathrm{Cu} / \mathrm{PPFC}$ nanocomposite thin films placed on a LED lamp.

The PTFE RF thin film exhibited excellent water repellency owing to its low surface energy. Figure 4 shows the water contact angle value of each sample for transmittance at $500 \mathrm{~nm}$. The pure PTFE, Cu 20 RF, and Cu 50 RF thin films showed almost similar transmittance, while their water contact angle decreased proportionally with increasing $\mathrm{Cu}$ content. This was because the amount of $\mathrm{Cu}$ contained in the thin film was so small that it did not affect the transmittance; however, the $\mathrm{Cu}$ was distributed on the surface and therefore affected the surface energy. For different power sources, the water contact angle decreased in the order $\mathrm{Cu} 80 \mathrm{RF}>\mathrm{Cu} 80 \mathrm{MF}>\mathrm{Cu} 80 \mathrm{DC}$, in the same order as their transmittance. Table 1 summarizes the water contact angle, sheet resistance, transmittance at $500 \mathrm{~nm}$, and $\mathrm{b}^{*}$ (yellow index) value of each sample. 


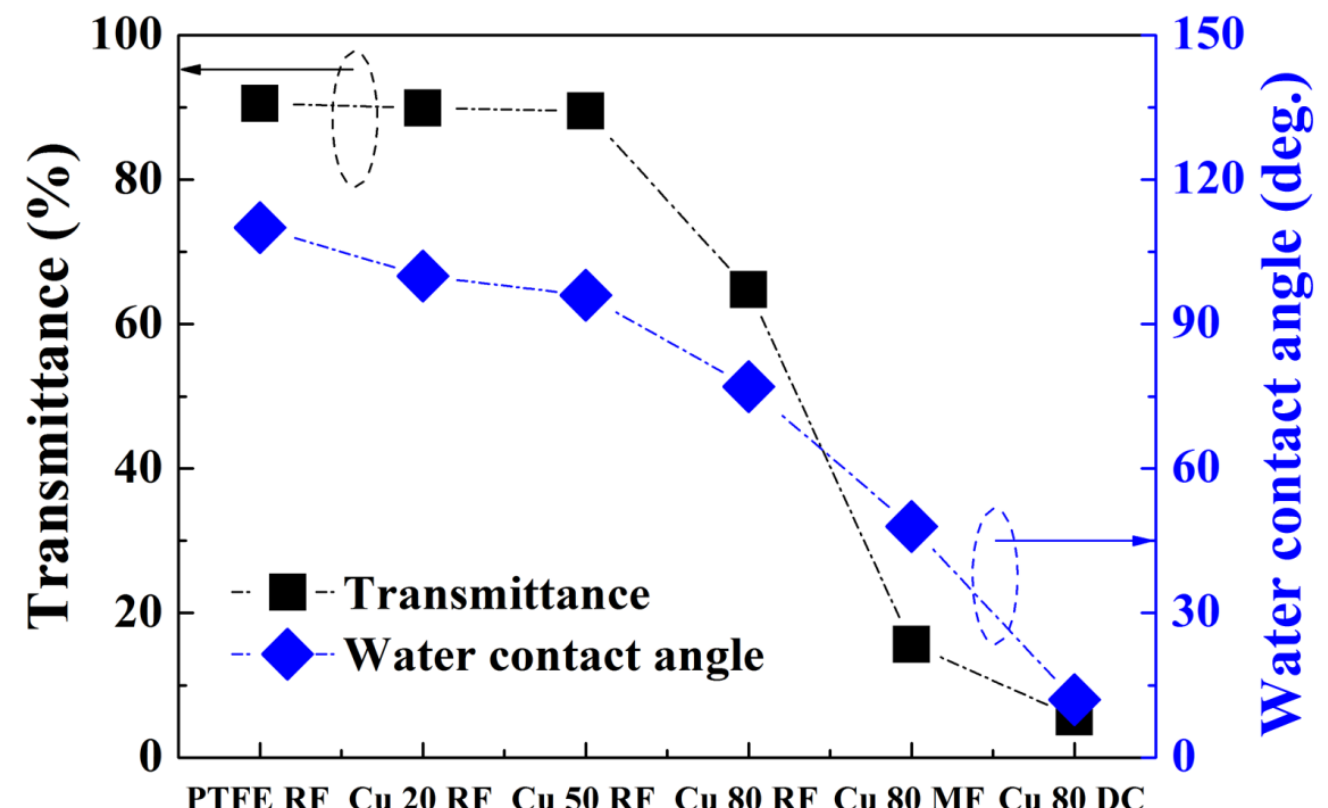

Figure 4. Optical transmittance at $500 \mathrm{~nm}$ for different $\mathrm{Cu}$ contents and power sources.

Table 1. Properties of $\mathrm{Cu} / \mathrm{PPFC}$ nanocomposite thin films using $\mathrm{Cu} / \mathrm{PTFE}$ composite targets. $\mathrm{b}^{*}$-yellow index.

\begin{tabular}{|c|c|c|c|c|c|}
\hline Target & Power Type & $\begin{array}{l}\text { Contact Angle } \\
\text { (deg.) }\end{array}$ & $\begin{array}{c}\text { Sheet Resistance } \\
(\Omega / \mathrm{sq})\end{array}$ & $\begin{array}{c}\text { Transmittance } \\
(\%)\end{array}$ & $\mathbf{b}^{*}$ \\
\hline Pure PTFE & RF & $109.83 \pm 0.42$ & over & $90.56 \pm 0.27$ & $0.69 \pm 0.06$ \\
\hline $\mathrm{Cu}$ 20/PTFE 80 & RF & $100.34 \pm 0.33$ & over & $89.92 \pm 0.29$ & $1.31 \pm 0.04$ \\
\hline Cu 50/PTFE 50 & $\mathrm{RF}$ & $95.85 \pm 0.44$ & over & $89.49 \pm 0.32$ & $1.37 \pm 0.04$ \\
\hline $\mathrm{Cu}$ 80/PTFE 20 & $\mathrm{RF}$ & $76.67 \pm 0.19$ & over & $64.80 \pm 0.33$ & $14.30 \pm 0.08$ \\
\hline Cu 80/PTFE 20 & MF & $12.10 \pm 0.48$ & $2.00 \pm 0.21\left(\times 10^{4}\right)$ & $15.68 \pm 0.21$ & $22.39 \pm 0.15$ \\
\hline $\mathrm{Cu}$ 80/PTFE 20 & DC & $48.31 \pm 0.33$ & $34.55 \pm 1.40$ & $5.62 \pm 0.11$ & $6.48 \pm 0.05$ \\
\hline
\end{tabular}

Figure 5 a shows the XRD patterns of the $\mathrm{Cu} / \mathrm{PPFC}$ nanocomposite thin films prepared by RF sputtering. The XRD pattern of the PTFE RF thin film shows a broad peak around $2 \theta=23^{\circ}$, implying that the thin film is amorphous. $\mathrm{Cu} 20 \mathrm{RF}$ also exhibited an amorphous state, indicating that the $\mathrm{Cu}$ content is randomly distributed in the polymer matrix without forming clusters. The XRD patterns of the $\mathrm{Cu} 50 \mathrm{RF}$ thin films showed Bragg peaks attributed to the (200) crystal face of $\mathrm{Cu}$ at $2 \theta \approx 50.6^{\circ}$. These results are clear evidence that the $\mathrm{Cu} / \mathrm{PPFC}$ nanocomposite is well formed. The $\mathrm{Cu} 80 \mathrm{RF}$ thin films showed Bragg peaks due to $\mathrm{CuF}_{2}$ and $\mathrm{Cu}_{2} \mathrm{O}$ crystals. Considering that the $\mathrm{Cu} / \mathrm{PPFC}$ nanocomposite thin film was fabricated in an argon atmosphere under vacuum, it is considered that the $\mathrm{Cu}_{2} \mathrm{O}$ crystal peaks were due to the oxidation of $\mathrm{Cu}$ when the thin film was exposed to air. Unexpectedly, $\mathrm{Cu}$ crystalline peaks were not observed in the $\mathrm{Cu} 80 \mathrm{RF}$ thin film. Figure $5 \mathrm{~b}$ shows the XRD patterns of the $\mathrm{Cu} 80 \mathrm{RF}, \mathrm{MF}$, and DC nanocomposite thin films. Unlike the $\mathrm{Cu} 80 \mathrm{RF}$ thin films, which only exhibit $\mathrm{CuF}_{2}$ and $\mathrm{Cu}_{2} \mathrm{O}$ crystal phases, the XRD patterns of the $\mathrm{Cu} / \mathrm{PPFC}$ nanocomposite thin films prepared by DC and MF sputtering show a $\mathrm{Cu}$ cubic crystal phase at $2 \theta \approx 40.5^{\circ}, \mathrm{Cu}_{2} \mathrm{O}$ cubic crystal phase at $2 \theta \approx 36.6^{\circ}$, and $\mathrm{CuCO}_{3}$ monoclinic crystal phase at $2 \theta \approx 25.8^{\circ}$ [32,33]. The fraction of the $\mathrm{Cu}$ crystal phase calculated from the XRD patterns of the $\mathrm{Cu} 80 \mathrm{MF}$ and $\mathrm{Cu} 80 \mathrm{DC}$ thin films was $14.2 \%$ and $21.1 \%$, respectively, whereas that in the $\mathrm{Cu} 80 \mathrm{DC}$ thin films showed larger values. The crystal size of the $\mathrm{Cu} 80 \mathrm{MF}$ and $\mathrm{Cu} 80 \mathrm{DC}$ thin films, as calculated by the Debye-Scherrer equation $(\mathrm{D}=0.916 \lambda / \beta \cos \theta, \mathrm{D}$ : Crystalline size, $\lambda:$ X-ray wavelength, $\beta$ : Full width half-maximum (FWHM) of Bragg peak, $\theta$ : Scattering angle), was about $5 \mathrm{~nm}$ [32]. 
(a)

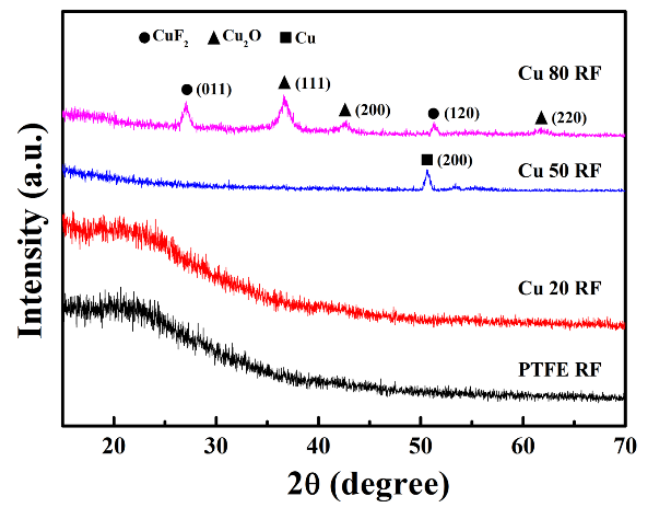

(b)

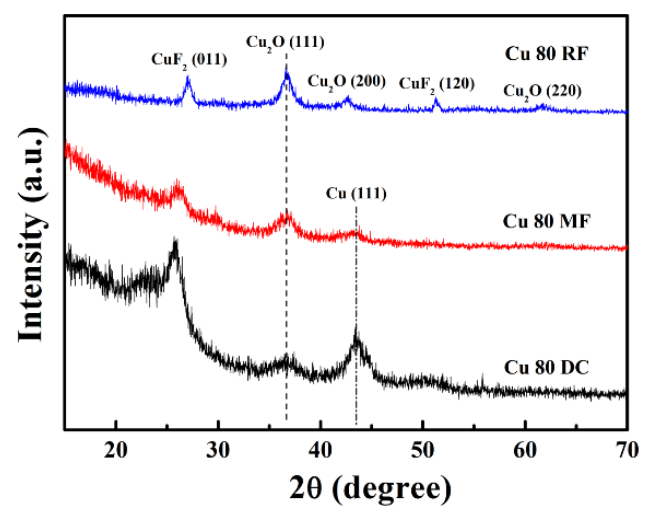

Figure 5. XRD patterns of (a) pure PTFE, Cu 20 RF, Cu 50 RF, Cu 80 RF, and (b) Cu 80 RF, Cu 80 MF, and $\mathrm{Cu} 80 \mathrm{DC}$ nanocomposite thin films.

The chemical structure of the $\mathrm{Cu} / \mathrm{PPFC}$ nanocomposite thin films was analyzed by XPS. The intensity of the binding energy was calibrated based on the position of the $\mathrm{C}-\mathrm{C}$ bond $\left(\mathrm{sp}^{3}\right.$ hybrid orbital, $284.8 \mathrm{eV}$ ). Figure 6a shows the normalized C 1s core-level XPS spectra of the Cu/PPFC nanocomposite thin films prepared by RF sputtering of the Cu/PTFE composite target. The $\mathrm{C} 1 \mathrm{~s}$ spectra exhibit broad Gaussian deconvolution peaks that have the following customary assignments for a fluorocarbon thin film: $294.0 \mathrm{eV}\left(\mathrm{CF}_{3}\right), 292.0 \mathrm{eV}\left(\mathrm{CF}_{2}\right), 289.8 \mathrm{eV}(\mathrm{CF}), 287.5 \mathrm{eV}\left(\mathrm{C}-\mathrm{CF}_{\mathrm{n}}\right)$, and an additional $\mathrm{C}=\mathrm{O}$ peak at $288.6 \mathrm{eV}$ owing to binding with oxygen $[16,31,34]$. The intensity of the $\mathrm{CF}_{2}$ bond, which is typical in a fluorocarbon thin film, is decreased owing to the low fluorine bonding ratio and high carbon bonding ratio in the thin film with increasing $\mathrm{Cu}$ content. In the $\mathrm{Cu} 80 \mathrm{RF}$ thin film, the composition ratio of fluorine was drastically decreased, and most of the bonds were formed between carbon and oxygen $(\mathrm{C}=\mathrm{O})$ upon exposure of the thin film to air. In the $\mathrm{Cu} 80 \mathrm{RF}$ thin film, the bonding ratio of fluorine decreased sharply, and the bond between carbon and oxygen $(\mathrm{C}=\mathrm{O})$ appeared after air exposure of the thin film. Figure $6 \mathrm{~b}$ shows that the $\mathrm{C} 1 \mathrm{~s}$ core-level spectra of the $\mathrm{Cu}$ $80 \mathrm{RF}, \mathrm{Cu} 80 \mathrm{MF}$, and $\mathrm{Cu} 80 \mathrm{DC}$ thin films have no binding energy peaks due to the $\mathrm{CF}_{2}$ bond, and that the carbon bond is dominant. The $\mathrm{Cu} 2 \mathrm{p}$ spectra of the $\mathrm{Cu} / \mathrm{PPFC}$ nanocomposite thin films are shown in Figure 6c. The $\mathrm{Cu} 20 \mathrm{RF}$ and $\mathrm{Cu} 50 \mathrm{RF}$ thin films showed almost no binding energy peak, whereas the $\mathrm{Cu} 80 \mathrm{RF}, \mathrm{Cu} 80 \mathrm{MF}$, and $\mathrm{Cu} 80 \mathrm{DC}$ thin films showed $\mathrm{Cu} 2 \mathrm{p}_{3 / 2}$ binding energy peaks at $932.7 \mathrm{eV}$ and a $\mathrm{Cu} 2 \mathrm{p}_{1 / 2}$ binding energy peak at $952.6 \mathrm{eV}(\triangle \mathrm{BE}=19.9 \mathrm{eV})$ [12]. In the $\mathrm{Cu} 80 \mathrm{RF}$ thin film, $\mathrm{CuCO}_{3}$ binding energy peaks were observed at $934.6 \mathrm{eV}\left(\mathrm{Cu} 2 \mathrm{p}_{3 / 2}\right)$ and $954.5 \mathrm{eV}\left(\mathrm{Cu} 2 \mathrm{p}_{3 / 2}\right)$, which is presumably due to surface oxidation after thin film fabrication. A shake-up satellite peak of $\mathrm{Cu}^{2+}[\mathrm{Ar}] 3 \mathrm{~d}^{9}$ orbital configuration was observed in the binding energy range of $938.5-946.0 \mathrm{eV}(\mathrm{Cu}$ $\left.2 \mathrm{p}_{3 / 2}\right)$ and $959.0-965 \mathrm{eV}\left(\mathrm{Cu} 2 \mathrm{p}_{1 / 2}\right)$. Shake-up satellite peaks appear strongly when $\mathrm{Cu}$ is oxidized to form $\mathrm{CuO}$ or $\mathrm{CuF}_{2}$. Thus, the $\mathrm{Cu} 80 \mathrm{DC}$ thin film exhibits excellent conductivity, a large crystal size of $\mathrm{Cu}$, as well as a low oxidation degree. Figure $6 \mathrm{~d}$ shows the chemical quantification results, obtained by considering the relative sensitivity factors of each binding energy peak in the XPS spectra. As the weight ratio of $\mathrm{Cu}$ increases from $\mathrm{Cu} 20 \mathrm{wt} . \%(9.12 \mathrm{~mol} \%)$ to $50 \mathrm{wt} . \%$ (20.8 $\mathrm{mol} \%$ ) and 80 $\mathrm{wt} . \%(51.2 \mathrm{~mol} \%)$ in the $\mathrm{Cu} / \mathrm{PTFE}$ composite target, the dramatic change in the physical properties of the $\mathrm{Cu} / \mathrm{PPFC}$ nanocomposite thin film is attributed to the difference in the quantitative ratio of copper atoms and fluorine atoms in the $\mathrm{Cu} / \mathrm{PPFC}$ nanocomposite thin film. $\mathrm{Cu}$ concentration of the nanocomposite thin films Cu $20 \mathrm{RF}(0.10 \%), \mathrm{Cu} 50 \mathrm{RF}(0.27 \%)$, and $\mathrm{Cu} 80 \mathrm{RF}(6.51 \%)$ were different from the composite targets but also gradually increased. 
(a)

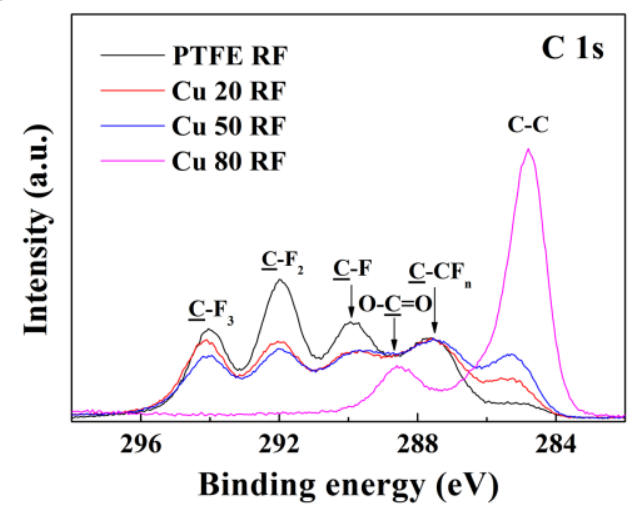

(c)

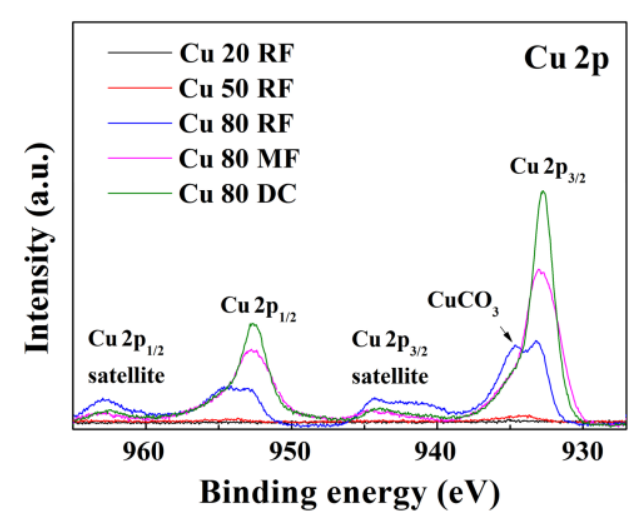

(b)

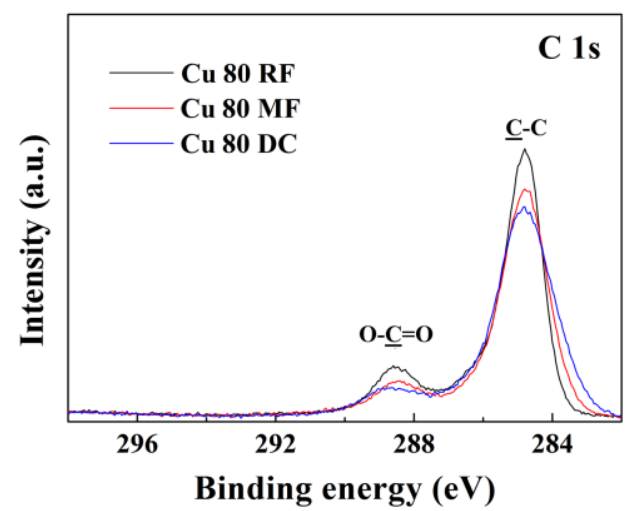

(d)

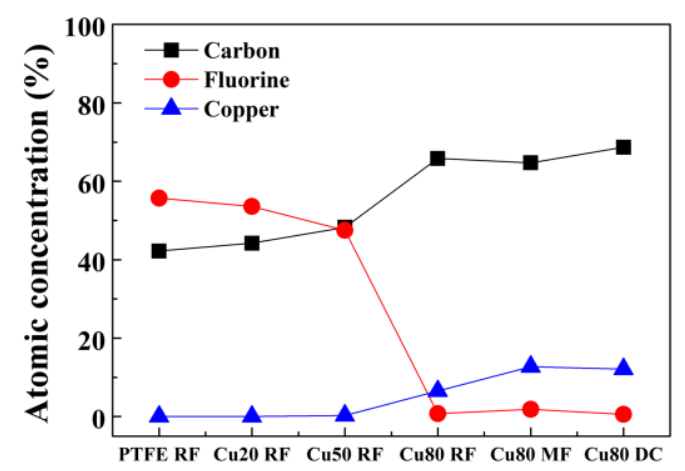

Figure 6. Normalized XPS spectra of (a) $C$ 1s with increasing $C u$ content, (b) $C$ 1s with RF, MF, and DC power sources, and (c) $\mathrm{Cu} 2 \mathrm{p}$ for the $\mathrm{Cu} / \mathrm{PPFC}$ nanocomposite thin films with varying $\mathrm{Cu}$ contents and power sources. (d) Calculated carbon, fluorine, and copper ratio for the nanocomposite $\mathrm{Cu} / \mathrm{PPFC}$ nanocomposite thin films.

\section{Conclusions}

In summary, we have successfully fabricated $\mathrm{Cu} / \mathrm{PTFE}$ composite targets with various $\mathrm{Cu}$ weight percentages for sputtering and deposited $\mathrm{Cu} / \mathrm{PPFC}$ nanocomposite thin films. This was followed by analysis of the properties of the $\mathrm{Cu} / \mathrm{PPFC}$ nanocomposite thin films with respect to the $\mathrm{Cu}$ composition ratio. The $\mathrm{Cu}$ nanoclusters were well distributed in a spherical shape with a size of 10-20 nm examined by a FE-TEM image. The $\mathrm{Cu} / \mathrm{PPFC}$ nanocomposite films prepared by RF sputtering with $\mathrm{Cu} 20$ and 50 targets showed very similar transmittance and color characteristics to those of pure PTFE. However, the water contact angle gradually decreased owing to the $\mathrm{Cu}$ on the film surface. The effect of $\mathrm{Cu}$ content was more pronounced in the $\mathrm{Cu} 80$ target. The $\mathrm{Cu} 80$ target has excellent conductivity and can be sputtered not only in RF but also in MF and DC power sources; moreover, the physical properties of the thin film change significantly depending on the power source. Interestingly, the $\mathrm{Cu} 80 \mathrm{MF}$ and $\mathrm{Cu} 80 \mathrm{DC}$ thin films exhibited absorption peaks at 618 and $678 \mathrm{~nm}$, respectively, indicating that the $\mathrm{Cu}$ nanoclusters were well formed. Further, from the red shift of the absorption peak, it can be assumed that the size of the nanoclusters prepared using DC was larger than that using MF, which is also why the nanocomposite films prepared by MF and DC exhibit sheet resistances of $2 \times 10^{4}$ and $34.55 \Omega / \mathrm{sq}$, respectively, thus explaining why the electrical properties of the thin films prepared using DC are superior.

This study describes a novel method to fabricate metal-polymer nanocomposites. This method can be expanded and diversified to easily fabricate not only various metal nanocomposites but also 
ceramics and semiconductor nanocomposites. Therefore, this method is industrially promising, as it enables fabrication over a large area and in a continuous manner.

Author Contributions: S.-J.L. designed the study and the experiments. S.H.K. fabricated the $\mathrm{Cu} / \mathrm{PPFC}$ thin films using a test sputter system. S.H.K., M.K., and J.S.P. analyzed the properties of the $\mathrm{Cu} / \mathrm{PPFC}$ thin films. S.-J.L. and M.K. wrote the manuscript. All of the authors discussed the results and commented on the manuscript.

Funding: This study was supported by the Core Research Project at Korea Research Institute of Chemical Technology (KRICT) (KK-1806-00) funded by the Ministry of Science and ICT.

Conflicts of Interest: The authors declare no conflict of interest.

\section{References}

1. Schurmann, U.; Takele, H.; Zaporojtchenko, V.; Faupel, F. Optical and electrical properties of polymer metal nanocomposites prepared by magnetron co-sputtering. Thin Solid Films 2006, 515, 801-804. [CrossRef]

2. Kreibig, U.; Vollmer, M. Optical properties of metal clusters; Springer-Verlag: Berlin, Germany, 1995.

3. Grynko, D.; Grytrsenko, K.; Lozovski, V.; Sopinskyy, M.; Strilchuk, G. Optical absorption of nano-composite thin films of Au in Teflon. Mater. Sci. Appl. 2010, 1, 141-151. [CrossRef]

4. Schurmann, U.; Hartung, W.; Takele, H.; Zaporojtchenko, V.; Faupel, F. Controlled syntheses of Ag-polytetrafluoroethylene nanocomposite thin films by co-sputtering from two magnetron sources. Nanotechnology 2005, 16, 1078-1082. [CrossRef]

5. Takele, H.; Greve, H.; Pochstein, C.; Zaporojtchenko, V.; Faupel, F. Plasmonic properties of Ag nanoclusters in various polymer matrices. Nanotechnology 2006, 17, 3499-3505. [CrossRef] [PubMed]

6. Choukourov, A.; Pihosh, Y.; Stelmashuk, V.; Biederman, H.; Slavínská, D.; Kormunda, M.; Zajíčková, L. Rf sputtering of composite $\mathrm{SiO}_{x}$ /plasma polymer films and their basic properties. Surf. Coat. Technol. 2002, 151-152, 214-217. [CrossRef]

7. Biswas, A.; Aktas, O.C.; Schürmann, U.; Saeed, U.; Zaporojtchenko, V.; Faupel, F.; Strunskus, T. Tunable multiple plasmon resonance wavelengths response from multicomponent polymer-metal nanocomposite systems. Appl. Phys. Lett. 2004, 84, 2655-2657. [CrossRef]

8. Beecroft, L.L.; Ober, C.K. Nanocomposite materials for optical applications. Chem. Mater. 1997, 9, 1302-1317. [CrossRef]

9. Zaporojtchenko, V.; Chakravadhanula, V.S.K.; Faupel, F.; Tamulevičius, S.; Andrulevičius, M.; Tamulevičiene, A.; Augulis, L. Residual stress in polytetrafluoroethylene-metal nanocomposite films prepared by magnetron sputtering. Thin Solid Films 2010, 518, 5944-5949. [CrossRef]

10. Wang, M.; Watanabe, S.; Miyake, S. Deposition of C-F thin films by sputtering and their micromechanical properties. Carbon Technol. 2005, 15, 29-36.

11. Zaporojtchenko, V.; Podschun, R.; Schurmann, U.; Kulkarni, A.; Faupel, F. Physico-chemical and antimicrobial properties of co-sputtered Ag-Au/PTFE nanocomposite coatings. Nanotechnology 2006, 17, 4904-4908. [CrossRef]

12. Cioffi, N.; Ditaranto, N.; Torsi, L.; Picca, R.A.; Sabbatini, L.; Valentini, A.; Novello, L.; Tantillo, G; Bleve-Zacheo, T.; Zambonin, P.G. Analytical characterization of bioactive fluoropolymer ultra-thin coatings modified by copper nanoparticles. Anal. Bioanal. Chem. 2005, 381, 607-616. [CrossRef] [PubMed]

13. Hedayati, M.K.; Faupel, F.; Elbahri, M. Tunable broadband plasmonic perfect absorber at visible frequency. Appl. Phys. A 2012, 109, 769-773. [CrossRef]

14. Hedayati, M.K.; Faupel, F.; Elbahri, M. Review of plasmonic nanocomposite metamaterial absorber. Materials 2014, 7, 1221-1248. [CrossRef] [PubMed]

15. Hedayati, M.K.; Javaherirahim, M.; Mozooni, B.; Abdelaziz, R.; Tavassolizadeh, A.; Chakravadhanula, V.S.K.; Zaporojtchenko, V.; Strunkus, T.; Faupel, F.; Elbahri, M. Design of a perfect black absorber at visible frequencies using plasmonic metamaterials. Adv. Mater. 2011, 23, 5410-5414. [CrossRef]

16. Cioffi, N.; Losito, I.; Torsi, L.; Farella, I.; Valentini, A.; Sabbatini, L.; Zambonin, P.G.; Bleve-Zacheo, T. Analysis of the surface chemical composition and morphological structure of vapor-sensing gold-fluoropolymer nanocomposites. Chem. Mater. 2002, 14, 804-811. [CrossRef]

17. Faupel, F.; Zaporojtchenko, V.; Strunskus, T.; Elbahri, N. Metal-polymer nanocomposites for functional applications. Adv. Eng. Mater. 2010, 12, 1177-1190. [CrossRef] 
18. Kelly, K.L.; Coronado, E.; Zhao, L.L.; Schatz, G.C. The optical properties of metal nanoparticles: The influence of size, shape, and dielectric environment. J. Phys. Chem. B 2003, 107, 668-677. [CrossRef]

19. Shi, G.; Araby, S.; Gibson, C.T.; Meng, Q.; Zhu, S.; Ma, J. Graphene platelets and their polymer composites: Fabrication, structure, properties, and applications. Adv. Funct. Mater. 2018, 28, 1706705. [CrossRef]

20. Idowu, A.; Boesl, B.; Agarwal, A. 3D graphene foam-reinforced polymer composites-A review. Carbon 2018, 135, 52-71. [CrossRef]

21. Mittal, G.; Rhee, K.Y.; Mišković-Stanković, V.; Hui, D. Reinforcements in multi-scale polymer composites: Processing, properties and applications. Compos. Part B Eng. 2018, 138, 122-139. [CrossRef]

22. Huang, Y.; Meng, X.; Xie, Y.; Wan, L.; Lv, Z.; Cao, J.J. Feng, Friction stir welding/processing of polymers and polymer matrix composites. Compos. Part A Appl. Sci. Manuf. 2018, 105, 235-257. [CrossRef]

23. Zhang, Y.H.; Qi, H.J. Composite fluorocarbon/ZnO films prepared by R.F. magnetron sputtering of $\mathrm{Zn}$ and PTFE. Surf. Coat. Technol. 2008, 202, 2612-2615. [CrossRef]

24. Kecskemeti, G.; Hopp, B.; Smausz, T.; Toth, Z.; Szabo, G. Production of porous PTFE-Ag composite thin films by pulsed laser deposition. Appl. Surf. Sci. 2012, 258, 7982-7988. [CrossRef]

25. Biswas, A.; Aktas, O.C.; Kanzow, J.; Saeed, U.; Strunskus, T.; Zaporojtchenko, V.; Faupel, F. Polymer-metal nanocomposites with tunable particle plasmon resonance prepared by vapor phase co-deposition. Mater. Lett. 2004, 58, 1530-1534. [CrossRef]

26. Biswas, A.; Márton, Z.; Kanzow, J.; Kruse, J.; Zaporojtchenko, V.; Faupel, F. Controlled generation of Ni nanoparticles in the capping layers of Teflon AF by vapor-phase tandem evaporation. Nano Lett. 2003, 3, 69-73. [CrossRef]

27. Ouyang, J.; Chu, C.W.; Szmanda, C.R.; Ma, L.; Yang, Y. Programmable polymer thin film and non-volatile memory device. Nat. Mater. 2004, 3, 918-922. [CrossRef]

28. Liu, C.; Fairhurst, R.G.; Ren, L.; Green, S.M.; Tong, J.; Arnell, R.D. Co-deposition of titanium/polytetrafluoroethylene films by unbalanced magnetron sputtering. Surf. Coat. Technol. 2002, 149, 143-150. [CrossRef]

29. Greve, H.; Pochstein, C.; Takele, H.; Zaporojtchenko, V.; Faupel, F. Nanostructured magnetic Fe-Ni-Co/Teflon multilayers for high-frequency applications in the gigahertz range. Appl. Phys. Lett. 2006, 89, 242501. [CrossRef]

30. Kamegawa, T.; Shimizu, Y.; Yamashita, H. Superhydrophobic surfaces with photocatalytic self-cleaning properties by nanocomposite coating of $\mathrm{TiO}_{2}$ and polytetrafluoroethylene. Adv. Mater. 2012, 24, 3697-3700. [CrossRef]

31. Kim, S.H.; Kim, C.H.; Choi, W.J.; Lee, T.G.; Cho, S.K.; Yang, Y.S.; Lee, J.H.; Lee, S.-J. Fluorocarbon thin films fabricated using carbon nanotube/polytetrafluoroethylene composite polymer targets via mid-frequency sputtering. Sci. Rep. 2017, 7, 1451. [CrossRef]

32. Valladares, L.D.L.S.; Salinas, D.H.; Dominguez, A.B.; Najarro, D.A.; Khondaker, S.I.; Mitrelias, T.; Barnes, C.H.W.; Aguiar, J.A.; Majima, Y. Crystallization and electrical resistivity of $\mathrm{Cu}_{2} \mathrm{O}$ and $\mathrm{CuO}$ obtained by thermal oxidation of $\mathrm{Cu}$ thin films on $\mathrm{SiO}_{2} / \mathrm{Si}$ substrates. Thin Solid Films 2012, 520, 6368-6374. [CrossRef]

33. Figueiredo, V.; Elangovan, E.; Goncalves, G.; Barquinha, P.; Pereira, L.; Franco, N.; Alves, E.; Martins, R.; Fortunato, E. Effect of post-annealing on the properties of copper oxide thin films obtained from the oxidation of evaporated metallic copper. Appl. Surf. Sci. 2008, 254, 3949-3954. [CrossRef]

34. Yamada, Y.; Kurobe, T. X-ray photoelectron spectroscopy of fluorocarbon films deposited by RF sputtering. Jpn. J. Appl. Phys. 1993, 32, 5090-5094. [CrossRef]

(C) 2019 by the authors. Licensee MDPI, Basel, Switzerland. This article is an open access article distributed under the terms and conditions of the Creative Commons Attribution (CC BY) license (http://creativecommons.org/licenses/by/4.0/). 